\title{
CHOOSING THE RIGHT MODEL: CONCEPTUAL MODELING FOR SIMULATION
}

\author{
Stewart Robinson \\ Warwick Business School \\ University of Warwick \\ Coventry, CV4 7AL, UK
}

\begin{abstract}
In performing a simulation study the modeler needs to make decisions about what to include in the simulation model and what to exclude. The modeler is faced with the very difficult choice of determining what is the best model to develop. Make it too complex and it may not be possible to complete the model with the time and knowledge available. Make it too simple and the results may not be sufficiently accurate. The process of determining what to model is known as conceptual modeling. In this paper we explore conceptual modeling first with an illustrative example from a healthcare setting. Conceptual modeling, its artefacts and requirements are then defined. Finally, a framework for helping a modeler to determine the conceptual model is briefly outlined.
\end{abstract}

\section{INTRODUCTION}

One of the most difficult issues in simulation modeling is determining the content of the simulation that is going to be developed. The job of the modeler is to understand the real system that is the subject of the simulation study and to turn this into an appropriate simulation model. The chosen model could range from a very simple single server and queue, through to a model that tries to encapsulate every aspect of the system. In effect, there are an infinite number of models that could be selected within this range, each with a slightly different content. The question is: which model is best? We explore the answer to this question in this paper.

On the surface we might suggest the answer is to build the model that contains as much detail as possible. After all, this model will be the closest to the real system and so surely the most accurate. This might be true if we had complete knowledge of the real system and a very large amount of time available to develop and run the model. But what if we only have limited knowledge of the real system and limited time? Indeed, we rarely have the luxury of vast quantities of either knowledge or time, not least because the real system rarely exists at the time of modeling (it is a proposed world) and a decision needs to be made according to a tight time schedule.

So, if we need to develop a simpler model, we need to determine the level of abstraction at which to work. This process of abstracting a model from the real world is known as conceptual modeling. We shall define conceptual modeling and the process of doing it in more detail in a while, but first it is useful to have a practical example to illustrate the issues involved in conceptual modeling.

\section{AN ILLUSTRATION OF CONCEPTUAL MODELING: SIMULATING AN OUTPATIENTS CLINIC}

Our simulation and modeling team was recently asked to develop a simulation model for a hospital in Birmingham, UK. The hospital was investing in a new outpatients building, a multi-million dollar project, and their key question was how many consultation rooms are required? They had performed some calculations based on expected patient flows and on observations of the current outpatients system. 
However, there was obviously some concern with making major investment decisions based on these limited data.

We were quick to point out the problems of making calculations based on static data which do not take into account the effects of variability in patient flows and consultation times. This is something for which discrete-event simulation is very well suited.

When asked to build a model such as this, the typical approach would be to start collecting data and to develop a detailed model of the system. However, the more we investigated how an outpatients system works the more we realized just how complex the system is. There are many specialties using the facility, each with its own clinical team. Patients can progress through a series of tests and consultations. For some specialties, such as ophthalmology, specialist equipment and dedicated rooms are required. Scheduling patient appointments is a significant task and then there is the matter of late arrivals and nonattendances. Staff shifts, working practices and skills all impact upon the functioning of the system.

Given appropriate data, it would be quite possible to build a simulation model that took account of all these details. There were, however, two issues that made such a model infeasible:

- Lack of data: much of the necessary data had not previously been collected and even if we were to try, issues of patient confidentiality (e.g. you cannot sit in a consultation room timing consultation times) would make it impossible to collect all the data we needed.

- Lack of time: the hospital required an answer within a few weeks and we had very limited time and resource to devote to the modeling work given the number of parallel activities in which we were engaged.

So what did we do? We focused on the critical issue of how many rooms were required and designed a simple model that would give at least an indication upon which the hospital managers could base a decision. Our world view was that the additional information a basic simulation could offer would be more beneficial than no simulation at all.

The simple model we constructed took a couple of days to build and experiment with. It provided a lower bound on the rooms required. In doing so it provided information that would give a greater level of confidence in making the decision that the hospital faced. This was all that was possible given the data and resource available, but it was still valuable.

The model we designed is outlined in Figure 1. Patient arrivals were based on the busiest period of the week - a Monday morning. All patients scheduled to arrive for each clinic, on a typical Monday, arrived into the model at the start of the simulation run, that is, 9:00am. For this model we were not concerned with waiting time, so it was not necessary to model when exactly a patient arrived, only the number that arrived.

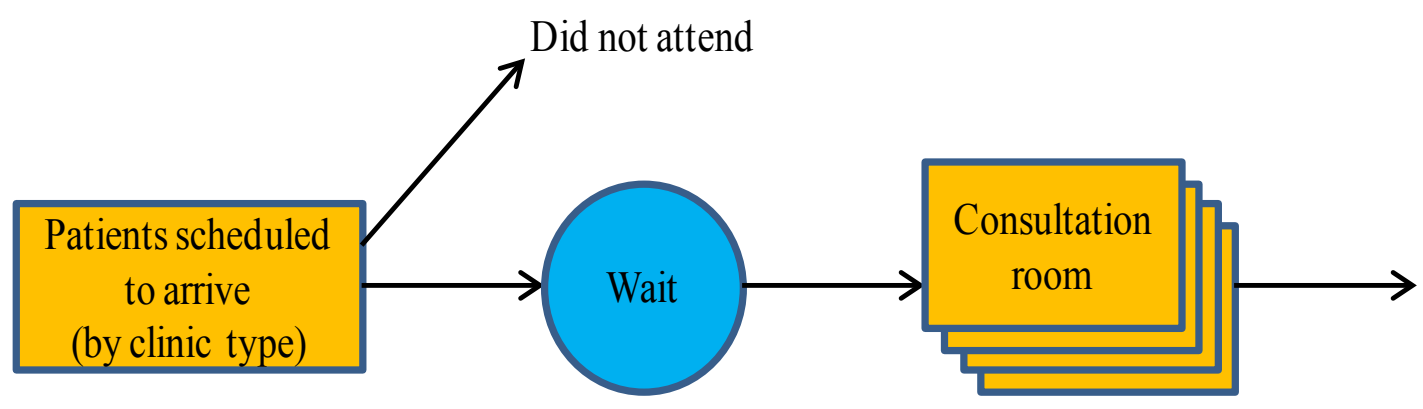

Figure 1: Simple Outpatients Building Model 
A proportion of patients do not attend their allotted clinic. Typical proportions of patients that do not attend were sampled at the start of the simulation run and these were removed before entering the waiting line.

Data on the time in a consultation room were limited, since they had not specifically been timed, but there were norms to which the clinical staff aimed to work. These data were available by clinic type and we used these as the mean of an Erlang-3 distribution to give an approximation for the variability in consultation time.

The input variable for the simulation experiments was the number of consultation rooms, which were varied from 20 to 60 in steps of 10 . The main output variable was the time it took until the last patient left the system. A key simplification, which all involved recognized, was that there were no limitations on staff or equipment availability. Albeit extremely unlikely that this would be the case, the model was predicting a lower bound on the rooms required. In other words, shortages of staff and equipment would only increase the need for consultation rooms with patients waiting in the rooms while the resource became available.

For each room scenario the model was replicated 1000 times and a frequency chart was generated showing the probability that the system would be cleared in under 3 hours - the hospital's target. Figure 2 shows an example of these results.

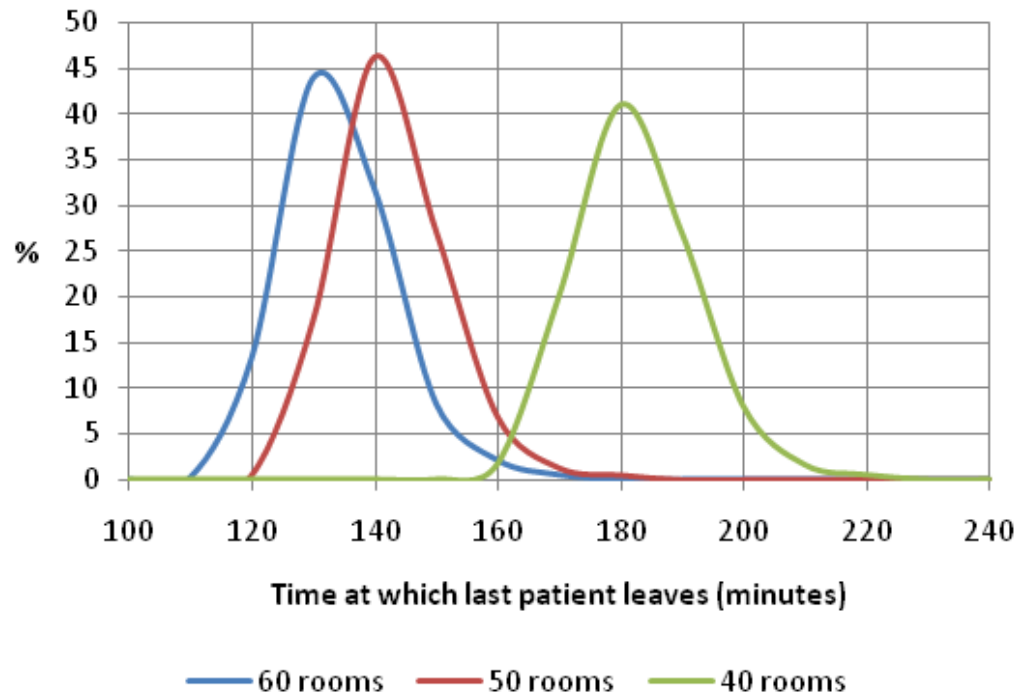

Figure 2: Example of Results from the Outpatients Building Model: Frequency Distributions for Time until Last Patient Leaves

This example illustrates the very essence of conceptual modeling; abstracting a model from the real system. In this case, the real system was not in existence, but it was a proposed system. The model involved simplifications such as modeling only Monday morning's clinic and not modeling staff and equipment. It also involved assumptions about, among others, the consultation times. Because of the constraints on data and time, the conceptual model involved a great deal of simplification; as such, it might be described as a 'far abstraction.'

Whether we got the conceptual model right is in large measure a matter of opinion and one we will leave the reader to judge. It is certain that readers will form quite different judgments on the credibility of the model and whether it was the best model or not.

\section{WHAT IS CONCEPTUAL MODELING?}

Conceptual modeling is the abstraction of a simulation model from the part of the real world it is representing ('the real system'). The real system may, or may not, currently exist. Abstraction implies 
the need for simplification of the real system and for assumptions about what is not known about the real system. In other words, all simulation models are simplifications of the real world. The secret to good conceptual modeling is to get the level of simplification correct, that is, to abstract at the right level.

Because all models are simplifications of the real world, all simulation modeling involves conceptual modeling. Even the most complex and detailed simulation still makes various assumptions about the real world and chooses to ignore certain details.

\subsection{Definition of a Conceptual Model}

More formally we define a conceptual model as follows:

'... a non-software specific description of the computer simulation model (that will be, is or has been developed), describing the objectives, inputs, outputs, content, assumptions and simplifications of the model.' (Robinson 2008a)

Let us explore this definition in some more detail. First, this definition highlights the separation of the conceptual model from the computer model. The latter is software specific, that is, it represents the conceptual model in a specific computer code. The conceptual model is not specific to the software in which it is developed. It forms the foundation for developing the computer code.

Second, it is stated that the description is of a computer simulation model that 'that will be, is or has been developed.' This serves to highlight the persistent nature of the conceptual model. It is not an artefact that gets created and is then dispensed with once the computer code has been written. It serves to document the basis of the computer model prior to development, during development and after development. Indeed, because the modeling process is iterative in nature (Balci 1994; Willemain 1995; Robinson 2004), the conceptual model is continually subject to change throughout the life-cycle of a simulation study.

Finally, the definition is completed by a list of what a conceptual model describes. It is vital that the objectives of the model are known in forming the conceptual model. The model is designed for a specific purpose and without knowing this purpose it is impossible to create an appropriate simplification. Consider what would have happened if the purpose of the outpatients building model had not been properly understood. We would almost certainly have been driven to a more general purpose, and by nature much more complex, model. Poorly understood modeling objectives can lead to an overly complex model. Instead, because the purpose of the model was clear we were able to create a very simple model.

It is useful to know the model inputs and outputs prior to thinking about the content of the model. The inputs are the experimental factors that are altered in order to try and achieve the modeling objectives. In the example above, this was the number of consultation rooms in the outpatients building. The outputs are the statistics that inform us as to whether the modeling objectives are being achieved (e.g. the time to clear all patients from the outpatient system) and if not, why they are not being achieved.

Knowing the objectives, inputs and outputs of the model help inform the content of the model. In particular, the model must be able to receive the inputs (e.g. it must model the consultation rooms) and it must provide the outputs (e.g. it must model the flow of patients until all have exited the system). The model content can be thought of in terms of the model scope (what to model) and the level of detail (how to model it).

The final two items in the list of what a conceptual model describes are the assumptions and simplifications of the model. These are quite distinct concepts (Robinson 2008a):

- Assumptions are made either when there are uncertainties or beliefs about the real world being modeled.

- Simplifications are incorporated in the model to enable more rapid model development and use, and to improve transparency. 
So, assumptions are a facet of limited knowledge or presumptions, while simplifications are a facet of the desire to create simple models.

\subsection{Artefacts of Conceptual Modeling}

To understand conceptual modeling further it is useful to set it within the wider context of the modeling process for simulation. Figure 3 shows the key artefacts of conceptual modeling. The 'cloud' represents the real world (current or future) within which the problem situation resides; this is the problem that is the basis for the simulation study. The four rectangles represent specific artefacts of the (conceptual) modeling process. These are as follows:

- System description: a description of the problem situation and the system in which the problem situation resides.

- Conceptual model: as defined in section 3.1

- Model design: the design of the constructs for the computer model (data, components, model execution, etc.) (Fishwick 1995).

- Computer model: a software specific representation of the conceptual model.

These artefacts are quite separate. This is not to say that they are always explicitly expressed, with the exception of the computer model. For instance, the system description, conceptual model and model design may not be (fully) documented and can remain within the minds of the modeler and the problem owners. It is, of course, good modeling practice to document each of these artefacts.

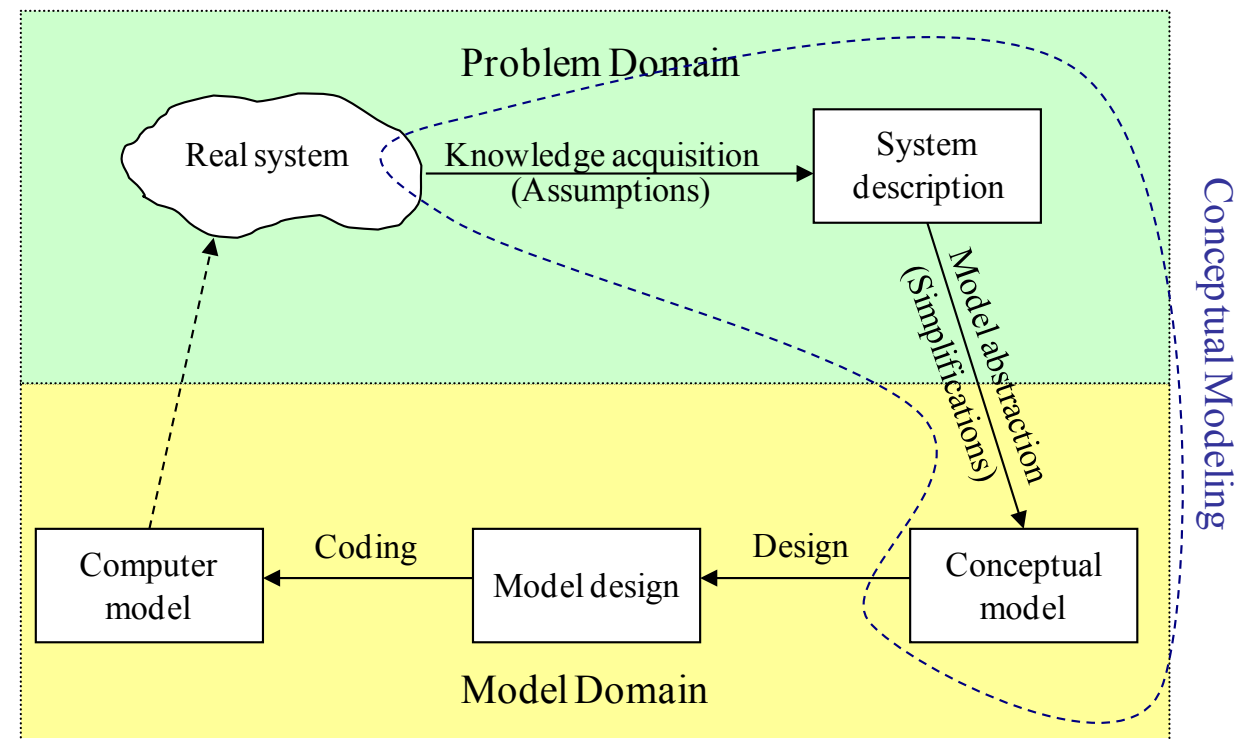

Figure 3: Artefacts of Conceptual Modeling (Robinson 2011)

The model design and computer model are not strictly part of conceptual modeling, but they do embody the conceptual model within the design and code of the model. These artefacts are included in Figure 3 for completeness. Our main interest here is in the system description and conceptual model which make up the process of conceptual modeling; as represented by the shape with a dashed outline in Figure 3. Unlike the model design and computer model, these two artefacts are independent of the software that will ultimately be used for developing the simulation model.

It is important to recognize the distinction between the system description and the conceptual model. The system description relates to the problem domain, that is, it describes the problem and the real world 
within which the problem resides. The conceptual model belongs to the model domain in that it describes those parts of the system description that are included in the simulation model and at what level of detail. The author's experience is that these two artefacts are often confused and seen as indistinct. Indeed, a major failure in any simulation project is to try and model the system description (i.e. everything that is known about the real system) and to not attempt any form of model abstraction; this leads to overly complex models.

The arrows in Figure 3 represent the flow of information, for instance, information about the real world feeds into the system description. The processes that drive the flow of information are described as knowledge acquisition, model abstraction, design and coding. The arrows are not specifically representative of the ordering of the steps within the modeling process, which we know are highly iterative (Balci 1994; Willemain 1995; Robinson 2004). In other words, a modeler may return to any of the four processes at any point in a simulation study, although there is some sense of ordering in that information from one artefact is required to feed the next artefact.

The dashed arrow shows that there is a correspondence between the computer model and the real world. The degree of correspondence depends on the degree to which the model contains assumptions that are correct, the simplifications maintain the accuracy of the model, and the computer code is free of errors. Because the model is developed for a specific purpose, the correspondence with the real world only relates to that specific purpose. In other words, the model is not a general model of the real world, but a simplified representation developed for a specific purpose. The issue of whether the level of correspondence between the model and the real world is sufficient is an issue of validation (Landry, Malouin, and Oral 1983; Balci 1994; Robinson 1999; Sargent 2008). Both conceptual modeling and validation are concerned with developing a simulation of sufficient accuracy for the purpose of the problem being addressed. As a result, there is a strong relationship between the two topics, conceptual modeling being concerned with developing an appropriate model and validation being concerned with whether the model is appropriate.

\section{REQUIREMENTS OF A CONCEPTUAL MODEL: WHAT IS GOOD?}

Before discussing how to perform conceptual modeling, let us consider what makes for a good conceptual model. The key requirements are that the model should be valid, credible, feasible and useful (Robinson 2008a). By these we mean the model should:

- Produce sufficiently accurate results for the purpose: understanding the number of rooms required in the building (validity).

- Be believed by the clients (credibility).

- Be feasible to build within the constraints of the available data and time.

- Be useful, that is, sufficiently easy to use, flexible, visual and quick to run.

Overarching all of this is the requirement to build the simplest model possible to meet the objectives of the simulation study. According to Innis and Rexstad (1983), Ward, (1989), Salt (1993), Chwif, Barreto, and Paul (2000), Lucas and McGunnigle (2003), and Thomas and Charpentier (2005), simpler models are preferred because:

- Simple models can be developed faster

- Simple models are more flexible

- Simple models require less data

- Simple models run faster

- The results are easier to interpret since the structure of the model is better understood 
As such, the need to abstract a conceptual model from the system description becomes even more pertinent. This does not, of course, mean that we should never develop more complex models, but that we should only develop them if they are required to meet the modeling objectives.

Figure 4 illustrates the relationship between model accuracy and model complexity (scope and level of detail). It shows that with increasing levels of complexity we obtaining diminishing returns in terms of accuracy, never reaching $100 \%$ accuracy. Eventually we may even find that the accuracy of the model reduces. This is because we do not have the knowledge or data to support the complexity that is being included in the model and we start to make assumptions that are incorrect.

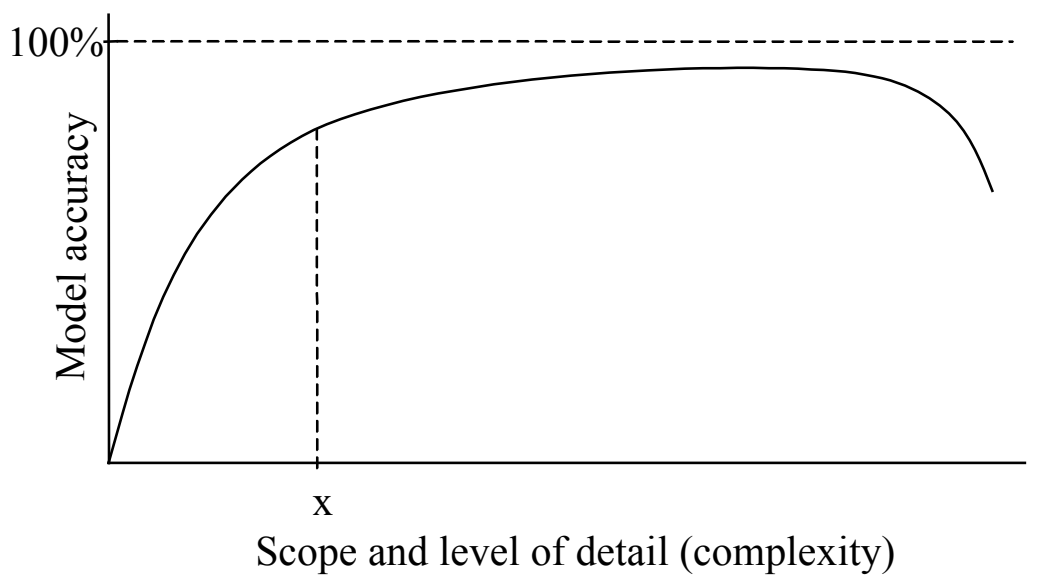

Figure 4: Simulation Model Complexity and Accuracy (Robinson 2008a)

So which is the best conceptual model? We might argue that the model at point $\mathrm{x}$ in Figure 4 is the best. At this point we have gained a high level of accuracy for a low level of complexity. Moving beyond $\mathrm{x}$ will only marginally increase accuracy and adding further complexity generally requires ever increasing effort. Of course, if we have a specific need for an accuracy level greater than that provided by $\mathrm{x}$, we will need to increase the complexity of the model.

The difficulty is in finding point $\mathrm{x}$. Conceptual modeling frameworks, such as the one outlined below, aim to help us in that quest, but conceptual modeling is more of an art than a science. As a result, we can only really hope to get close to $\mathrm{x}$. In other words, there may be a 'best' model, but we are extremely unlikely to find it among an infinite set of models. What we should hope to do is identify the best model we can. As such, our quest is for better models, not necessarily the best.

\section{A FRAMEWORK FOR CONCEPTUAL MODELING}

A framework for conceptual modeling provides a set of steps that guide a modeler through the development of a conceptual model. This is a subject that has received only very limited attention in the simulation literature. Here a very brief outline of a framework for conceptual modeling is given. For a more detailed account, and an illustration of the framework in use, see Robinson (2008b). There are also some alternative conceptual modeling frameworks presented in Robinson et al. (2011).

Figure 5 outlines the conceptual modeling framework. In this framework, conceptual modeling involves five activities that are performed roughly in this order:

- Understanding the problem situation

- Determining the modeling and general project objectives

- Identifying the model outputs (responses)

- Identify the model inputs (experimental factors) 
- Determining the model content (scope and level of detail), identifying any assumptions and simplifications

Starting with an understanding of the problem situation, a set of modeling and general project objectives are determined. These objectives then drive the derivation of the conceptual model, first by defining the outputs (responses) of the model, then the inputs (experimental factors), and finally the model content in terms of its scope and level of detail. Assumptions and simplifications are identified throughout this process.

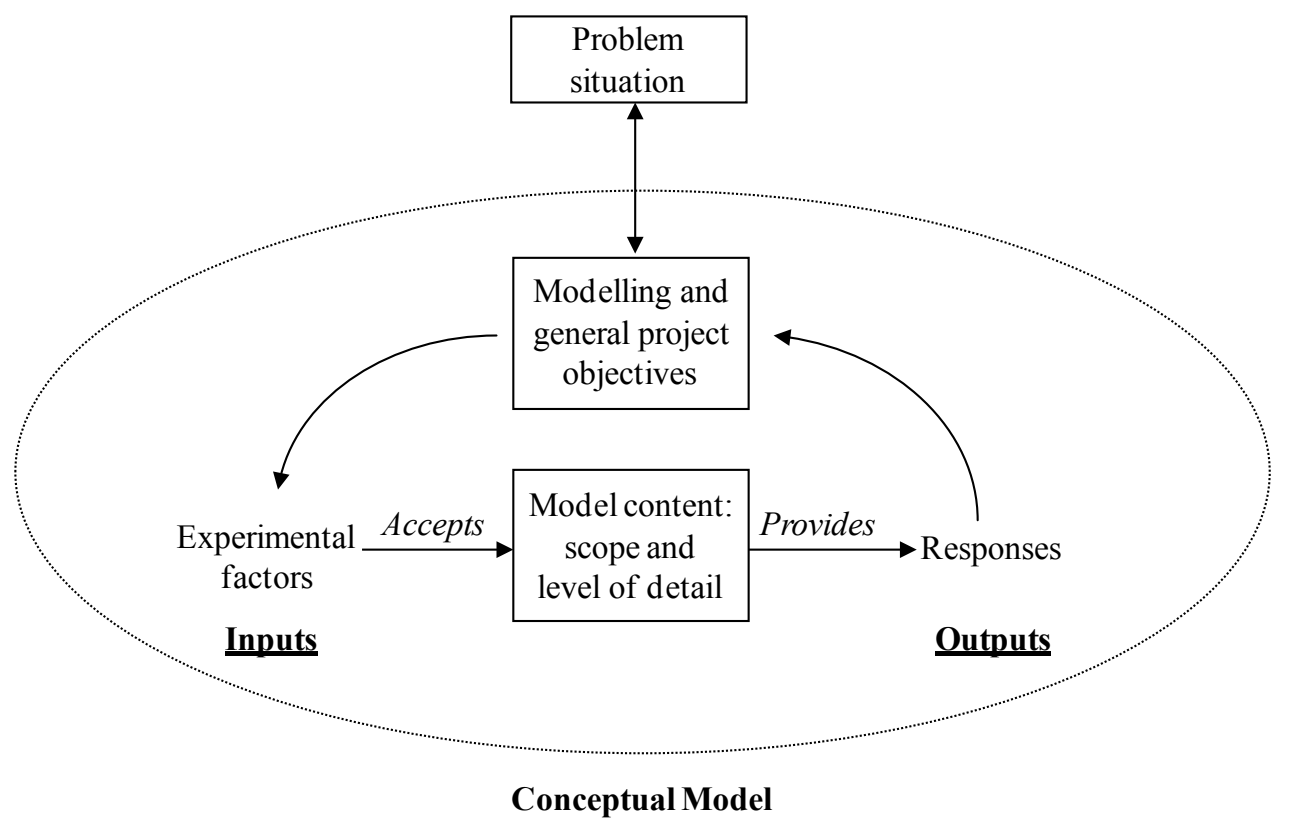

Figure 5: A Framework for Conceptual Modeling (Robinson 2008b)

The ordering of the activities described above is not strict. Indeed, we would expect much iteration between these activities and with the other activities involved in a simulation study: data collection and analysis, model coding, verification and validation, experimentation and implementation.

The framework is supported by a conceptual model template which provides a set of tables that describe each element of the conceptual model. These tables describe:

- Modeling and general project objectives (organisational aim, modeling objectives, general project objectives)

- Model outputs/responses (outputs to determine achievement of objectives, outputs to determine reasons for failure to meet objectives)

- Experimental factors

- Model scope

- Model level of detail

- Modeling assumptions

- Model simplifications

The modeler works through these tables with the support of the stakeholders and domain experts, iteratively improving them to the point that the modeler and stakeholders are satisfied that the conceptual model meets the requirements for validity, credibility, feasibility and utility. This provides a structured 
framework for making the conceptual modeling decisions explicit (documentation) and for debating ways of improving the conceptual model. The appendix provides an illustration of the conceptual model template using the example of a simple fast food restaurant problem.

\section{CONCLUSION}

Conceptual modeling is the abstraction of a simulation model from a real world system. It is probably the most important aspect of any simulation study. Get the conceptual model right and the rest of the simulation work will be more straightforward, providing the right information in the right time-scale.

This paper provides an illustration of how appropriate conceptual modeling, through a far abstraction, made a simulation study feasible within the constraints of data and time available. The discussion that follows defines conceptual modeling, its artefacts and its requirements. From this base, a framework for conceptual modeling is outlined. The framework aims to guide a modeler through the process of creating and documenting a conceptual model.

Conceptual modeling is not a science, but an art. As with any art, it can be learned and it can be improved upon with experience. Frameworks provide a good way of learning about conceptual modeling and for helping to do it better. At present, however, there are very few examples of conceptual modeling frameworks and this is an area where more research needs to be undertaken.

\section{ACKNOWLEDGEMENTS}

I acknowledge the help of Claire Worthington (Warwick Business School) in the modeling of the outpatients building. I am also grateful for the financial support of the Strategic Lean Implementation Methodology Project (SLIM) (www2.warwick.ac.uk/fac/soc/wbs/projects/slim) which is funded by the Warwick Innovative Manufacturing Research Centre.

Sections of this paper are based on Robinson, S. 2010. "Conceptual Modelling: Who Needs It?" SCS Modeling \& Simulation Magazine 1 (2): April. www.scs.org/magazines/201004/index_file/Files/Robinson.pdf; Robinson, S. 2011. "Conceptual Modeling for Simulation.” In Encyclopedia of Operations Research and Management Science, Edited by J.J. Cochran, forthcoming. New York: Wiley; Robinson, S. 2001. "Designing Simulations that are Better than the Rest: Conceptual Modelling for Simulation". Keynote paper, Young OR Conference, Nottingham, 2011. Birmingham, UK: The Operational Research Society.

\section{APPENDIX: EXAMPLE OF THE CONCEPTUAL MODEL TEMPLATE}

The problem: a fast food restaurant is experiencing problems with one of the branches in its network. Customers regularly complain about the length of time they have to queue at the service counters. It is apparent that this is not the result of shortages in food, but a shortage of service personnel.

\section{Project}

Fast Food Restaurant

\section{Modeling and General Project Objectives}

Organisational Aim

To improve customer service levels

Modeling Objectives

The number of service staff required during each period of the day to ensure that $95 \%$ of customers queue for less than 3 minutes for service. Due to space constraints, a maximum of 6 service staff can be employed at any one time. 
General Project Objectives

\begin{tabular}{|l|l|}
\hline Time-scale & 5 working days \\
\hline Flexibility & Limited (extensive changes unlikely) \\
\hline Run-speed & Many experiments to be run \\
\hline Visual display & Simple 2D \\
\hline Ease-of-use & Use by modeler only \\
\hline
\end{tabular}

\section{Model Outputs/Responses}

Outputs (to determine achievement of objectives)

Percentage of customers queuing for less than 3 minutes

Outputs (to determine reasons for failure to meet objectives)

Bar chart of waiting time for each customer in the queues, mean, standard deviation, minimum and maximum

Time-series of mean queue size by hour

Staff utilisation (cumulative percentage)

\section{Experimental Factors}

Staff rosters (total number of staff in each hour of the day), varied over a range of 1 to 6

\section{Model Scope}

\begin{tabular}{|c|c|c|}
\hline Component & Include/Exclude & Justification \\
\hline \multicolumn{3}{|l|}{ Entities: } \\
\hline Customers & Include & Flow through the service process \\
\hline \multicolumn{3}{|l|}{ Activities: } \\
\hline Service points & Include & $\begin{array}{l}\text { Experimental factor, required for staff utilization } \\
\text { response }\end{array}$ \\
\hline Tables & Exclude & Not related to waiting for food \\
\hline Cooking & Exclude & $\begin{array}{l}\text { Assumption: material shortages are not a signifi- } \\
\text { cant problem }\end{array}$ \\
\hline Cleaning & Exclude & Not related to speed of service \\
\hline \multicolumn{3}{|l|}{ Queues: } \\
\hline Service point queues & Include & $\begin{array}{l}\text { Required for waiting time and queue size re- } \\
\text { sponse }\end{array}$ \\
\hline Table queues & Exclude & Tables are not being modeled \\
\hline Queues of food & Exclude & $\begin{array}{l}\text { Assumption: material shortages are not a signifi- } \\
\text { cant problem }\end{array}$ \\
\hline \multicolumn{3}{|l|}{ Resources: } \\
\hline Service staff & Exclude & Simplification: represented by service points \\
\hline Kitchen staff & Exclude & Cooking not being modeled \\
\hline Cleaning staff & Exclude & Cleaning not being modeled \\
\hline
\end{tabular}


Model Level of Detail

\begin{tabular}{|c|c|c|c|}
\hline Component & Detail & $\begin{array}{l}\text { Include/ } \\
\text { Exclude }\end{array}$ & Justification \\
\hline \multicolumn{4}{|l|}{ Entities: } \\
\hline \multirow[t]{4}{*}{ Customers } & \multirow{4}{*}{$\begin{array}{l}\text { Quantity: } 1 \text { entity represents } 1 \\
\text { customer group } \\
\text { Arrival pattern: inter-arrival } \\
\text { time distribution varying } \\
\text { over the day } \\
\text { Attributes: size of customer or- } \\
\text { der } \\
\text { Routing: to shortest queue }\end{array}$} & Include & \multirow{4}{*}{$\begin{array}{l}\text { Simplification: removes need to } \\
\text { model individual customers and } \\
\text { then to group them } \\
\text { Required to model customer demand } \\
\text { Simplification: represented in the } \\
\text { service time } \\
\text { Impacts on waiting time and queue } \\
\text { size responses }\end{array}$} \\
\hline & & Include & \\
\hline & & Exclude & \\
\hline & & Include & \\
\hline \multicolumn{4}{|l|}{ Activities: } \\
\hline \multirow[t]{7}{*}{ Service points } & \multirow{7}{*}{$\begin{array}{l}\text { Quantity: number available } \\
\text { each hour of the day } \\
\text { Nature (X in Y out) } \\
\text { Cycle time: service time distri- } \\
\text { bution (accounts for order } \\
\text { size and variability in staff } \\
\text { performance) } \\
\text { Breakdowns/repairs } \\
\text { Set-up/changeover } \\
\text { Resources } \\
\text { Shifts: number available each } \\
\text { hour of the day } \\
\text { Routing: to world } \\
\text { Other: Absenteeism }\end{array}$} & Include & Experimental factor \\
\hline & & Exclude & Simple 1 in 1 out \\
\hline & & Include & $\begin{array}{l}\text { Represents workload and so utiliza- } \\
\text { tion of staff (response) }\end{array}$ \\
\hline & & $\begin{array}{l}\text { Exclude } \\
\text { Exclude } \\
\text { Exclude }\end{array}$ & $\begin{array}{l}\text { Assumption: assume no breakdowns } \\
\text { n/a } \\
\text { No resources modeled }\end{array}$ \\
\hline & & Include & Experimental factor \\
\hline & & Include & $\begin{array}{l}\text { Not modeling further activities in the } \\
\text { restaurant e.g. tables }\end{array}$ \\
\hline & & Exclude & $\begin{array}{l}\text { Simplification: if required can be } \\
\text { modeled by perturbations to the } \\
\text { number of staff available }\end{array}$ \\
\hline \multicolumn{4}{|l|}{ Queues: } \\
\hline \multirow[t]{6}{*}{$\begin{array}{l}\text { Service point } \\
\text { queues }\end{array}$} & \multirow{6}{*}{$\begin{array}{l}\text { Quantity: one for each service } \\
\text { point } \\
\text { Capacity: unlimited } \\
\text { Dwell time } \\
\text { Queue discipline: FIFO }\end{array}$} & Include & Required for queuing responses \\
\hline & & Exclude & $\begin{array}{l}\text { Simplification: no limit to number of } \\
\text { people who can wait }\end{array}$ \\
\hline & & Exclude & \\
\hline & & Include & $\begin{array}{l}\text { Simplification: no pushing in to } \\
\text { queues and no balking, jockeying or } \\
\text { leaving from queues. }\end{array}$ \\
\hline & & Exclude & \\
\hline & & Include & Flow of entities through the system \\
\hline $\begin{array}{l}\text { Resources: } \\
\mathrm{n} / \mathrm{a}\end{array}$ & & & \\
\hline
\end{tabular}


Modeling Assumptions

Material shortages are not a significant problem

Assume no breakdowns of service points

\section{Model Simplifications}

Service staff represented by the service points

1 entity represents 1 customer group

Size of customer order represented in the service time distribution

Absenteeism modeled through perturbations to the number of staff available

No pushing in to queues, no balking, no jockeying or no leaving from queues

No limit to number of people who can wait in a queue

\section{REFERENCES}

Balci, O. 1994. "Validation, Verification, and Testing Techniques Throughout the Life Cycle of a Simulation Study." Annals of Operations Research 53: 121-173.

Chwif, L., M.R.P. Barretto, and R.J. Paul. 2000. "On Simulation Model Complexity.” In Proceedings of the 2000 Winter Simulation Conference, Edited by J.A. Joines, R.R. Barton, K. Kang, and P.A. Fishwick, 449-455. Piscataway, New Jersey: Institute of Electrical and Electronics Engineers, Inc.

Fishwick, P.A. 1995. Simulation Model Design and Execution: Building Digital Worlds. Upper Saddle River, New Jersey: Prentice-Hall, Inc.

Innis, G., and E. Rexstad. 1983. "Simulation Model Simplification Techniques." Simulation 41 (1): 7-15.

Landry, M., J.L. Malouin, and M. Oral. 1983. "Model Validation in Operations Research." European Journal of Operational Research 14 (3): 207-220.

Lucas, T.W., and J.E. McGunnigle. 2003. "When is Model Complexity too Much? Illustrating the Benefits of Simple Models with Hughes' Salvo Equations." Naval Research Logistics 50: 197-217.

Robinson, S.1999. "Simulation Verification, Validation and Confidence: A Tutorial." Transactions of the Society for Computer Simulation International 16 (2): 63-69.

Robinson, S. 2004. Simulation: The Practice of Model Development and Use. Chichester, UK: Wiley.

Robinson, S. 2008a. "Conceptual Modelling for Simulation Part I: Definition and Requirements". Journal of the Operational Research Society 59 (3): 278-290.

Robinson, S. 2008b. "Conceptual Modelling for Simulation Part II: A Framework for Conceptual Modeling." Journal of the Operational Research Society 59 (3): 291-304.

Robinson, S. 2011. "Conceptual Modeling for Simulation." In Encyclopedia of Operations Research and Management Science, Edited by J.J. Cochran, forthcoming. New York: Wiley.

Robinson, S., R.J. Brooks, K. Kotiadis, and D.J. van der Zee. 2011. Conceptual Modelling for DiscreteEvent Simulation. FL, USA: Taylor and Francis.

Salt, J. 1993. "Simulation Should be Easy and Fun." In Proceedings of the 1993 Winter Simulation Conference, Edited by G.W. Evans, M. Mollaghasemi, E.C. Russell, and W.E. Biles, 1-5. Piscataway, New Jersey: Institute of Electrical and Electronics Engineers, Inc.

Sargent, R.G. 2008. "Verification and Validation of Simulation Models." In Proceedings of the 2008 Winter Simulation Conference, Edited by S.J. Mason, R.R. Hill, L. Mönch, O. Rose, T. Jefferson, and J.W. Fowler, 157-169. Piscataway, New Jersey: Institute of Electrical and Electronics Engineers, Inc.

Schruben, L. W. 1979. "Designing Correlation Induction Strategies for Simulation Experiments." In Current Issues in Computer Simulation, Edited by N. R. Adam and A. Dogramaci, 235-256. New York: Academic Press.

Thomas, A., and P. Charpentier. 2005. "Reducing Simulation Models for Scheduling Manufacturing Facilities." European Journal of Operational Research 161 (1): 111-125.

Ward, S.C. 1989. "Arguments for Constructively Simple Models." Journal of the Operational Research Society 40 (2): 141-153. 
Willemain, T.R. 1995. "Model Formulation: What Experts Think About and When." Operations Research 43 (6): 916-932.

\section{AUTHOR BIOGRAPHY}

STEWART ROBINSON is Professor of Operational Research and Head of the Operational Research and Management Sciences Group at Warwick Business School. Previously employed in simulation consultancy, he supported the use of simulation in companies throughout Europe and the rest of the world. $\mathrm{He}$ is author/co-author of four books on simulation. His research focuses on the practice of simulation model development and use. Key areas of interest are conceptual modeling, model validation, output analysis and alternative simulation methods (discrete-event, system dynamics and agent based). He is currently helping to lead a research project that is investigating the use of simulation with lean in healthcare. Professor Robinson is co-editor of the Journal of Simulation and Vice President of the United Kingdom Operational Research Society. For more details see: www.btinternet.com/ stewart.robinson1/sr.htm. His email is stewart.robinson@warwick.ac.uk. 